\title{
Mentoring Associate Teachers in Initial Teacher Education: The Value of Dialogic Feedback
}

\author{
Luke Jones, Steven Tones and Gethin Foulkes \\ Faculty of Education and Children's Services, University of Chester, Parkgate Road, \\ Chester, UK
}

\begin{abstract}
Purpose - The aim of this paper is to analyse feedback in the context of secondary initial teacher education (ITE) in England. More specifically, it aims to examine the feedback experiences of physical education (PE) subject mentors and their associate teachers (ATs) during a one-year postgraduate programme.
\end{abstract}

Design/methodology/approach - Semi-structured interviews, with nine PE mentors and eleven ATs within a university ITE partnership, were used to explore lesson feedback and the context in which it was provided. Interview data from the twenty participants was analysed through constant comparison to categorise content and identify patterns of responses.

Findings - Mentors were well versed in the formal feedback mechanism of a written lesson observation. This approach is well established and accepted within ITE, but the dialogic feedback that follows lessons was thought to be where ATs made most progress. These learning conversations were seen to provide less formal but more authentic feedback for those learning to teach, and were most successful when founded on positive and collaborative relationships between the mentor and the ATs.

Practical implications - These findings have implications for providers of teacher education and more specifically how they approach mentor training. The focus on lesson observations has value, but examining more informal dialogic approaches to feedback may have more impact on the learning of ATs.

Originality/value - These findings support the value of lesson feedback but challenge the primacy of formal written lesson observations. The learning conversations that follow lessons are shown to provide authentic feedback for ATs.

Key words - dialogic feedback, learning conversations, physical education, mentor, associate teacher, initial teacher education

Paper type - Case study 


\section{Introduction}

\section{Initial teacher education}

Since September 2012, the achievement of associate teachers (ATs) (also known as preservice or trainee teachers) within initial teacher education (ITE) in England has been judged against national Teachers' Standards. The standards outline the minimum level of competence expected of ATs and are also used to assess their progress towards qualified teacher status (Department for Education [DfE], 2013). As such, providers of ITE must ensure that the design and delivery of their programmes allow ATs to meet the standards; ATs, in turn, are expected to demonstrate their competence in relation to this framework. ATs typically do this by collating the formal lesson observations that have been written by their mentor or sometimes by other experienced teachers in the school. The ATs' professional learning, and their progress towards qualified teacher status, is influenced by a range of factors, but perhaps most significantly by the mentors who are responsible for providing support during this process (Lofthouse, 2017). As such, mentoring is a significant feature of ITE programmes. The mentor is usually a school-based colleague with relevant subject experience; a key feature of the mentor's role is to provide formative feedback to ATs on their ability to plan, teach and assess learning (Lofthouse, 2017). This process inevitably involves regular and varied feedback conversations, although relatively little research has explored the nature of the dialogue between the mentor and AT in this context.

Against the backdrop of the expectations and conventions of ITE, this paper explores the perceptions of mentor feedback in teacher education through the eyes of nine physical education (PE) mentors and eleven PE ATs. Drawing upon data gathered from one-to-one interviews with the PE mentors and ATs, the paper examines how feedback is provided, what value it has for PE ATs and how it might be improved.

\section{Literature Review}

\section{The value offeedback}

The process of teaching and learning is commonly characterised as being more effective when feedback is used to recognise progress, engage the learner and identify the next steps (Hattie, 2011). Effectively implementing feedback does seemingly lead to more obvious and significant improvements in understanding and performance. A meta-analysis of effective teaching approaches conducted by Coe et al. (2014) identified formative assessment approaches, such as effective questioning, reviewing prior learning and allowing time to 
respond to feedback, as being specific practices associated with high-quality pedagogy. Similarly, an independent review commissioned by the Sutton Trust for the Education Endowment Foundation has examined research findings on the impact of different teaching interventions. As part of this work, Higgins et al. (2013) cast doubt on the value of a range of previously accepted approaches, but also identified a number of cost effective strategies, with the provision of effective feedback being the teaching approach with the greatest effect size.

There is less available evidence on the impact of feedback within ITE, but Coe et al. (2014) believe that the learning process for ATs is similar to that of pupils, and that the findings can also be applied to adults who are learning to teach. As such, mentor feedback is positioned as a key aspect of an AT's learning. Timperley et al. (2007) highlight the value of mentor feedback being linked to clear and challenging targets, being informed by an assessment of pupil learning and being located in a supportive learning environment where ATs have multiple opportunities to reflect on, practice and apply their learning. The importance of a non-threatening learning environment is similarly raised by Hinchey (2010, p. 6) who notes that "Teachers whose work can be improved but who are feeling at risk may understandably be inclined to hide, rather than confront, their problems-precluding valuable formative feedback". This may be a problem with more formal lesson observation approaches, discussed below, as Copland (2010) highlights the tension that can exist for both mentors and ATs during post-lesson feedback.

\section{Formal feedback and monological mentoring}

A formal lesson observation is a well-established means of providing feedback in ITE. It is completed by the mentor, with comments being written on a standardised form about the perceived strengths and areas for development evident in the lesson. The formal nature of the written lesson observation allows transient aspects of teaching and learning to be captured and to be used as evidence of progress against the Teachers' Standards (DfE, 2013). More importantly, the written comments are a source of feedback for ATs and are shared after the lesson - often during the weekly 'mentor meeting'. The expectation is for mentors to provide feedback to ATs, based on written comments made against specific criteria. They aim to develop the pedagogical skills and understanding of ATs by considering the different aspects of their teaching and in particular the impact that this has had on pupil learning. Timperley et al. (2007) identify this as a particularly important aspect of professional learning, as the ATs' ability to assess pupil learning accurately is seen as the basis of self-regulation. In this way, 
the feedback provided by mentors should, it is argued, lead ATs to reflect on pupil outcomes so that they can use an assessment of pupil learning to inform their own understanding of how to teach effectively.

The formal lesson observation is firmly established within ITE as a criterion-based approach that retains features of what Bokeno and Gantt (2000) refer to as monological mentoring. In this model, the expert teacher directs the AT towards a clearly defined end point, with predetermined criteria being used to measure progress and provide feedback along the way (Nahmad-Williams and Taylor, 2015). It is thought that monological mentoring approaches can be particularly useful for solving ATs' immediate problems and for developing their organisational and behaviour management skills (Wang and Odell, 2002). Feedback that is provided by the expert through direct instruction to the novice can be highly successful in achieving clearly defined aims (Ko et al., 2014; Wang and Odell, 2002). Indeed, feedback is thought to be more useful when based on explicit criteria (Hattie, 2011) and directly related to intended learning outcomes (James and Pollard, 2011). That said, there are reservations about the use of a hierarchical, expert-novice model where ATs are positioned as more passive recipients of knowledge (Cassidy et al., 2004; Charteris and Smardon, 2014). This is characteristic of what Hobson (2016) called 'judgementoring', where one-way conversations about competency allow less room for reflection, innovation and discovery. Monological feedback can direct ATs to reproduce existing and dominant models of teaching and learning (Nahmad-Williams and Taylor, 2015; Wang and Odell, 2002).

\section{Informal feedback and dialogical mentoring}

In contrast to more formal criterion-based approaches, less structured, conversational feedback is also provided to ATs. Informal approaches are distinct from conventional methods of lesson feedback that are centred on the need for ATs to gather evidence against the Teachers' Standards (DfE, 2013). With more informal mentor feedback, there is no written observation form to complete, and the dialogue that follows flows from what has happened in the lesson itself, rather than from targeted criteria. Feedback is seemingly now a more open and spontaneous two-way conversation about learning to teach. Senge (1990) advocates the idea of people learning together through dialogue. He maintained that open discussion promotes shared thinking and allows those involved to uncover what may otherwise have remained hidden. Isaacs (1993) similarly argued that new levels of insight and 
changes in behaviour could arise from open dialogue where individuals are genuinely interested in exploring ideas and thoughts together.

When adopting what Bokeno and Gantt (2000) termed a dialogic model, mentors are not expected to simply deliver pedagogical knowledge to ATs but to promote inquiry and reflection and to use collaborative learning conversations to develop thinking and shared understanding (Nahmad-Williams and Taylor, 2015). Adopting this approach reframes the relationship of the mentor and AT and positions them as a collaborative and reciprocal partnership, working together to extend their understanding (Cassidy et al., 2004; Lofthouse and Wright, 2012; Wang and Odell, 2002). For Bokeno and Gantt (2000), meaningful dialogue depends on all of those involved in the interaction having a genuine care and respect for each other, being willing to engage in reflection and being able to share thoughts and ideas authentically. This understanding builds on the work of Senge (1990, p. 9) who noted that "learningful" conversations are ones that "balance inquiry and advocacy, where people expose their own thinking effectively and make that thinking open to the influence of others".

\section{Summary}

Mentoring has been the focus of a wealth of research in recent years but remains a difficult concept to define, not least because of the varied relationships and complex aspects of interaction that are involved (Nahmad-Williams and Taylor, 2015). Monological and dialogical mentoring have been identified by Bokeno and Gantt (2000) as two models that help us begin to make sense of the interactions that take place between the mentor and the AT. More specifically, they provide a useful context for analysing the different approaches that are used to provide feedback to ATs. Feedback, for all its complexity, is clearly positioned as a key aspect of learning (Coe et al., 2014; Higgins et al., 2013; Ko et al., 2014) but less is known about what constitutes effective feedback in the context of ITE, especially in relation to PE. As such, this paper will explore perceptions of feedback, with a particular focus on the potential value of dialogic mentoring. It will examine how feedback is provided to PE ATs, the value of the different approaches used and how mentoring and feedback might be improved.

\section{Methods}

The study consisted of one-to-one interviews with nine mentors and eleven ATs in eleven secondary schools in North West England. All PE ATs on the ITE programme took part in 
the study, while two mentors declined the invitation to participate. The ATs were completing a yearlong postgraduate qualification in secondary education, with 120 days of the 180-day programme being based in schools. Interviews were conducted at the end of the ITE programme.

The selection of schools was based on a purposive sample where the settings were included or excluded based on their relevance to the purposes of the study (Roberts, 2009). In this case, all schools were part of the ITE PE partnership of a single university in North West England. The second level of sampling involved the teachers and ATs within the secondary schools. Purposive sampling was again used to select potential participants, with the inclusion criteria being based on whether or not the teachers were responsible for mentoring PE ATs or whether or not the ATs were training to teach PE. All those sampled were directly involved in the PE ITE partnership and were able to speak widely on the topic to provide an understanding of the relationships and context that they worked within. This sampling strategy allowed the researchers to develop understanding from the different perspectives of PE mentors and PE ATs and was thought to be a particularly useful means of investigating the nature of feedback in PE ITE (Bryman, 2012).

All participants were interviewed separately in a quiet and secluded office space at the mentors' schools. Semi-structured interviews were used, whereby the standardised nature of most of the questions allowed for relatively easy comparison between the data gathered from different respondents at different sites (Bryman, 2012). There was also some latitude to ask follow-up questions, thereby enabling interviewees to elaborate and explain their thoughts and experiences in greater depth. By adopting this technique, the researcher had the flexibility to enter into a dialogue with the mentors and ATs, to clarify more complex issues and elicit data that may otherwise have remained uncovered (Gratton and Jones, 2010). This approach allowed the researcher a deeper level of insight into respondents' thoughts and experiences, as they not only enabled the interviewer to capture the views of the respondent, but also to understand the context, relationships and constraints that influence their everyday life (Denzin and Lincoln, 2011).

While probing for additional answers may have provided a richer level of information, the use of semi-structured interviews does create a problem of comparing non-standard responses. Analysis of data is more complex when using semi-structured interviews than 
when respondents are restricted to a more formal and structured approach (Bryman, 2012). In this study, the interviews conducted with mentors and ATs were audio recorded, transcribed into Word documents and then analysed to determine the presence, meaning and relationships of certain words or concepts. Key incidents in the data were identified and labelled based on a comparison with the groups that already existed. The key words or concepts were then clustered together to reconnect the data and make sense of the links between the separate parts. The process of identifying and then categorising data, based on comparison with what has already been grouped, is known as coding (Roberts, 2009). This systematic procedure is considered an effective strategy for analysing data and has become a commonly used approach within qualitative research. By deconstructing and describing the data in this way, it is thought possible to interpret findings and identify themes in a relatively detached manner (Gratton and Jones, 2010).

The sub-headings in the Findings express the themes that emerged from the data. The individual mentors and associate teachers are identified by their role (M or AT) and a number reflecting their position in the sequence of interviews.

\section{Findings}

How is feedback provided to, and received by, PE associate teachers?

The formal lesson observation is deeply rooted in teacher education. It is a well-established practice that PE mentors will have experienced themselves during their own training and commonly features as part of school and university-based mentor training. It is perhaps not surprising therefore that when asked about feedback mechanisms, all mentors and ATs referred to formal written feedback on standardised university forms. A number of other mechanisms also emerged, often reflecting the favoured approaches of mentors. Written comments or notes on non-standardised forms featured in two thirds of the schools, while annotating lesson plans to provide feedback before the teaching episode was an approach used by half the mentors. Other less frequently used feedback mechanisms included: video recording lessons; peer feedback from other ATs in the department; sharing pupil feedback; verbal feedback from the mentor during and after the lesson; and demonstrations of alternate teaching approaches. The most frequently reported form of feedback, however, was the informal discussion between the PE mentor and the AT following almost all lessons. One mentor noted that "continuous verbal feedback is very important in their development; I spend a great deal of time informally discussing issues, ideas and events that have occurred 
within lessons. I focus on this informal dialogue throughout the PGCE placements ... as this is an effective way of enabling students to vocalise their thoughts in a relaxed environment" (M1).

Having consistent access to frequent feedback was valued by PE ATs for two main reasons. Firstly, they wanted reassurance particularly early on in their placement, when they were less certain about the quality of their teaching: "You don't start with that confidence at the start of the year, so you do need to be told" (AT5); "You feel like you need more feedback because you don't know really what you are doing" (AT11); "You don't know if it's good or bad if they're not giving you feedback" (AT4). Secondly, not getting feedback was a real source of frustration for ATs when they had put time and effort into the planning and teaching of the lesson: "It makes me quite annoyed, because I've planned that whole entire lesson and then I've got nothing back. I feel like I've put so much time into it; if someone can't watch it, why am I bothering?" (AT3).

While it was clear that PE ATs valued consistent feedback, they were not prepared for how they would receive it. One AT noted, "We were never told were we? It just kind of happens when and how your mentor thinks you need it most" (AT7). Similarly, despite claiming that they welcomed regular evaluations of their teaching, many ATs also conceded that they would avoid asking for feedback from some teachers (not all lessons were observed by the AT's mentor). This avoidance was typically related to the respect that they had for the teacher, based on their experience or lack of it, their familiarity with contemporary teaching approaches or their perceived ability as teachers. A common theme that was shown to undermine relationships and compromise the desire to ask for feedback was the adoption of a 'do what I say, not what I do' approach. One PE AT noted that it is "annoying when they are not a good role model" (AT10), while another asked, "How can you expect me to do that when you're not even doing it?" (AT11). The AT avoided feedback because of his frustration at being expected to maintain standards that the teacher did not or could not demonstrate himself.

\section{The changing nature of feedback throughout the year}

When PE mentors were asked more specifically about the nature of the feedback that they provided, it became clear that it is processual in nature. All mentors recognised that their approach changed and adapted over the duration of the year in relation to the progress made 
by the AT, with one mentor noting, "I feel that I go through something of a journey with the PGCE students" (M1). Over half the PE mentors commented that they provided lengthier formal feedback at the start of the placement and were more likely to interject in lessons at this time too: "My feedback is more detailed when students start, while more established students will have less, but more critical feedback" (M6). A similar number of mentors also noted that feedback was very positive and promoting in its nature at the start of the year, but increasingly critical as ATs made progress: "Feedback is always extremely positive in the first couple of months when they are starting out. It's so important to build confidence first. As the AT progresses they are given more constructive feedback to ensure they are meeting expectations" (M4). A further consequence of rising expectations was that feedback focused on increasingly challenging aspects of pedagogy as the training year progressed:

The feedback tends to focus on the basics of being a good teacher ... at the start of a placement. This progresses to more challenging tasks such as deeper questioning, better assessment procedures and developing more individual learning as the placement goes on. (M3)

Finally, comments from the PE mentors also showed that feedback moved from more general aspects of pedagogy to being far more specific and personalised: "The feedback towards the end of the placement would be more specific, geared to the trainees' needs and what they need to work on, whereas early on in the placement it tends to be more general" (M8).

At the start of the training year, PE ATs seemingly have more detailed feedback relating to what are perceived to be more generic and less demanding areas of pedagogy. At this point, mentors are aiming to establish the basic pedagogical skills and understanding of ATs while also looking promote their confidence in the classroom. Towards the end of the year, lesson observations are supplemented with more informal discursive feedback that is more specific and critical in its nature, reflecting the individual needs of the PE AT and the raised expectations of the mentor to tackle more demanding aspects of pedagogy. The ATs themselves noticed a similar pattern, where initial written feedback rewarded effort and enthusiasm and aimed to embed generally simplistic aspects of good practice such as following school routines and policies: "At the start it [feedback] was all about the basics of teaching, following department policies and getting involved" (AT5). Written feedback 
continued, allowing ATs to gather evidence for the Teachers' Standards, but alongside this, more focused discursive feedback was also provided.

While there was a general pattern towards more specific and critical discursive feedback, PE mentors also acknowledged that the organisation of the PE curriculum into activity areas often meant that they had to revert to more simplistic subject knowledge and confidenceenhancing feedback when ATs were faced with the challenge of teaching new activities for the first time: "Our expectations of the ATs changes as the year goes by; however, as the activities change every six weeks there is a sense that the trainees sometimes need to learn again for each sport" (M9). PE ATs also recognised this and admitted that they sometimes felt completely overawed when teaching a new activity area, and that only receiving negative comments in this circumstance did not help them make progress. They had all experienced this in one way or another and wanted the opportunity to go back to observe the mentor teach lessons when faced with a completely new area of the curriculum:

We agreed that for athletics, to start with I was just going to watch him with regards to health and safety, how he's going to organise something. From there I got a clearer idea. I know if I observe it I'll be able to do it myself then. (AT7)

Mentors and ATs accepted that while all forms of feedback became increasingly critical throughout the year, there was also a need to be flexible and to alter the levels of expectation and support in response to the AT's experience of teaching different areas of the curriculum.

\section{What is the perceived value of the different approaches used to provide feedback?}

PE mentors and ATs recognised that not only did the focus of feedback change during the training year, but so too did the mechanism for providing feedback. Initially, there was greater reliance on formal lesson observations, where comments written on a standardised form were discussed in depth during designated mentor meetings. The formal lesson observations continued over the year, but more informal and dialogic feedback mechanisms were also increasingly used as ATs took responsibility for teaching more lessons. Over three quarters of the mentors described the feedback as involving an open and productive two-way discussion that came to follow almost every lesson. There were many pragmatic reasons that PE mentors put forward to justify the move towards informal learning discussions at the end of a lesson. It was thought to be: less daunting for associate teachers, helping them to relax 
and focus on the lesson; more timely and flexible, making it better suited to the demands of a busy school day; and more appropriate for the number of lessons taught, allowing for frequent monitoring of progress and needs. One mentor noted, "The informal meetings are more valuable for ATs. It's not so daunting for them, and a quick 'this worked' or 'why didn't this go to plan?' can go a long way" (M3). More importantly, all mentors believed that informal discussions about pedagogy were valuable as a supportive, constructive and meaningful means of providing feedback to ATs. One mentor spoke for all in saying,

This is where most learning takes place. I like to discuss areas of the lesson and physically model or explain certain areas for improvement. I think these discussions and demonstrations about what went well or could be better, play a massive part in the development of trainee teachers. (M8)

PE ATs similarly noted that feedback became more informal yet authentic as the year progressed. Authentic feedback, that was honest, valid and personalised in its nature, was welcomed, as it was increasingly related to their actual teaching rather than being focused on achieving the teaching standards. One AT explained his frustration with the formal approach: "Feedback isn't about what you did in the lesson; it's about what you've got to do next on the list of standards" (AT4). As such, formal lesson observations were seen to be about "playing the game" (AT5), a contrived process of collecting evidence that put undue pressure on ATs when they were trying to teach: "Standards are stressful!" (AT1). In contrast, PE ATs felt that with informal and dialogic feedback approaches, they had reached a point where it was assumed that they were competent and could be trusted to lead groups effectively. This brought confidence and allowed for more useful, authentic and open discussions about their teaching. There was less anxiety associated with informal, dialogic feedback, which led to more meaningful conversations. One AT explained,

They start to assume that you are okay; once you are into it, they're like, 'Yes, she's good, she's fine', and that in itself gives you confidence. And then it's just talking about the lesson in a positive way but helping to spot ways of being better. It seems to flow a bit easier. (AT11)

At this point, ATs felt that they had progressed to a stage where they were trusted and respected as teachers: "My mentor is really good at making you feel like an equal, like we're 
proper teachers" (AT10). This was especially evident when their mentor asked them for help or advice about an aspect of teaching: "I love it when they take ideas from the way I've been teaching them. To see that is really nice" (AT5). While another AT noted that "It worked best when I felt I was on the same level as the mentor, in that we got on and shared ideas and approaches. It really works" (AT4). The development of a positive and collaborative relationship with the PE mentors was seen to be at the heart of informal dialogic feedback.

\section{How might mentoring and feedback be improved?}

Informal dialogic approaches that reduced evaluation apprehension and allowed for more immediate and authentic feedback were seen by PE mentors to be the most productive: "I feel that the continual feedback through informal dialogue is very much the most beneficial [approach]" (M2); "Regular verbal [feedback] is the right way, with plenty of praise and small meaningful targets that build confidence and encourage them to think" (M4); "I feel immediate feedback is most beneficial when trying to fine tune [ATs'] skills and push the learning process" (M6). None of the mentors believed that a formal lesson observation was the best form of feedback for those learning to teach PE. That is not to say that mentors did not see any value in formal feedback processes, as they accepted that this approach enabled PE ATs to gather evidence against the standards and meet the conventions of ITE. As such, formal lesson observations were thought to be a useful part of the process, but not the best approach for promoting the teaching skills of ATs: "A combination of formal and informal feedback is probably most beneficial, especially early on, but informal discussions for me tend to illicit the best response from the ATs" (M1).

PE ATs similarly expressed a preference for more regular but less formal feedback. They appreciated the value of more detailed feedback at the start of the year but were happy to move to a model where they were having regular open discussions about specific aspects of pedagogy, discussions that promoted confidence and genuinely helped them to make progress: "It's just the time after the lesson, where we review, say what worked and what improvements can be made for next time. It reassures you you're doing alright and gives a focus to work on" (AT1).

Given their preference for more informal dialogic feedback, it is perhaps not surprising that when PE mentors and ATs were asked to provide advice on the mentoring process, their comments were focused on this approach. Over half the mentors highlighted the value of 
positive dialogue and supportive relationships: "Feedback must ultimately be as positive as possible with areas for improvement being discussed openly" (M8). They also referred to the importance of mentors providing consistent and constructive feedback that was clearly focused on personalised targets. One mentor summarised this process neatly by saying that,

Mentors should get to know the AT and give appropriate feedback that suits their requirements. Try to be as positive as you can be but ensure the areas for improvements are presented in a manner that leads them to work out for themselves what needs to be addressed. (M9)

All PE ATs similarly felt that effective feedback was based on having a good relationship with their mentor, so that their time in school was a positive collaborative experience: "I think it's good when they get to know you a bit more. I want to be open with them so that we can have a good discussion about it" (AT6). Finally, respecting and valuing the AT as an individual teacher also featured strongly, as did the desire for the mentor to be supportive and empathetic: "I think they forget how difficult it is. You want someone who will be critical, but also someone you know is on your side" (AT2). While there was agreement on the value of positive and supportive interactions, ATs were emphatic in stating how critical the relationship with their mentor was to their learning.

\section{Discussion}

PE mentors provide lesson feedback to their ATs in many different ways, but two dominant approaches emerged: the formal written lesson observation and the more informal dialogic feedback that follows teaching episodes. The former is well established within PE ITE and meets the need for ATs to gather evidence against the Teachers' Standards (DfE, 2013) as they move towards qualified teacher status. This, then, is criterion-referenced feedback that fits with a monological model of mentoring (Bokeno and Gantt, 2000), where the written comments that are made about the ATs' progress are structured around a list of competencies. In contrast, the informal feedback that follows a lesson is commonly, but not always, identified as being an open and productive two-way discussion. Feedback is not provided to the AT in a conventional sense as the interaction with the mentor becomes a collaborative reflection where thoughts and ideas are explored together. This approach is more consistent with a dialogical model of mentoring where shared understanding develops from open and meaningful interactions (Bokeno and Gantt, 2000). 
Mentors play varying roles when interacting with ATs (Collet, 2015). This is evident when they provide feedback, as mentors move between different and overlapping models in response to the ATs' needs. In general, mentors typically begin with standardised formal feedback that aims to promote confidence while also embedding more general and basic pedagogical practices. Over time, there is more reliance on a dialogic approach, with feedback being increasingly personalised and critical in relation to more challenging aspects of teaching and learning. As feedback is developmental and contextually bound (Castanheira, 2016), mentors adapt and refine their approach in relation to the needs of the AT and in doing so face the challenge of nurturing and judging progress at the same time. Mentors are seemingly in a somewhat contradictory position as the conventions of ITE mean that they are required to formally assess ATs while also being expected to nurture their development through supportive and non-evaluative relationships (Hobson, 2016).

The criterion-based lesson observation is generally accepted by PE mentors and ATs but is seen as a means to an end. It is thought to be most useful as a way of capturing transient moments of teaching as written comments - comments that can then be used as documented evidence of progress against the teaching standards (DfE, 2013). Nonetheless, there were reservations about monological approaches and the use of the standards being associated with what Hobson and Malderez (2013) termed judgementoring. ATs were apprehensive at the thought of being assessed, and this was thought to impede, rather than promote, their teaching. ATs also found the continual reference to standards to be somewhat artificial and lacking in authenticity, as feedback was determined by the need to gather evidence for particular standards, rather than being specifically tailored to their point of development as individual learners (Bokeno and Gantt, 2000).

In contrast, the dialogic feedback approach allowed for elements of 'ONSIDE' (Off-line, Non-evaluative, Supportive, Individualised, Developmental and Empowering) mentoring of ATs (Hobson, 2016) rather than the judgementoring approach that has been found to increase anxiety and impede professional learning. The dialogic approach was adopted in part as a pragmatic response to the increased number of lessons that were being taught by the PE AT in a busy school day. It allowed for immediate and frequent feedback in manageable units (Shute, 2008). Moreover, a move to a more informal, dialogic approach was thought to create a personalised experience and promote greater progress. The quality of the discussion helped 
learning. Lofthouse (2017, p. 1) draws attention to effective mentor-AT conversations as being a "transformative space where important aspects of professional practice are debated and emerging professional identities, both as a new teacher and a mentor, can be constructed". In the best cases, mentoring was shown to involve 'doing something with someone as opposed to' the learner (Cassidy et al., 2004), with the focus being on a form of professional collaboration. Mullen and Lick (1991) describe collaboration as 'energising walkways', and this was evident in the dialogic feedback of PE mentors and ATs. When individuals (mentor and AT) are brought together, the learning conversations between both can begin to create a new partnership, which in turn energises learning. The dialogic approach to feedback was thought to elicit more authentic and personalised discussions that energised ATs (and perhaps their mentors) and ultimately led to greater progress and learning.

A changing balance from written lesson observations towards more informal dialogic feedback was seen to be appropriate by PE mentors and ATs, but the latter was still favoured for its greater impact on learning. That said, while ATs valued these learning conversations, they were more likely to seek any type of feedback from the mentors and other teachers that they respected and trusted. A supportive learning environment promoted the ATs' desire to ask for and respond to feedback (Timperley et al., 2007). The ATs also felt, in turn, that dialogic feedback worked best when they themselves were trusted and respected by their mentor. A positive collaborative relationship was at the heart of effective dialogic feedback. PE mentors are in a pivotal position to influence (both positively and negatively) the learning and development of ATs (Garza et al., 2014). In order for learning to be more positively charged, it is clear that mentors should aim to establish a trusting and respectful relationship with their ATs (Nicolaidou et al., 2016), and some means of doing so are suggested by our analyses. In the first instance, discussing with PE ATs how they would like to receive feedback may be helpful in developing a trusting and respectful relationship. This did not occur in any setting and arguably contributed to an unhelpful conception of mentoring being something that is 'done to' ATs (Cassidy et al., 2004). The dialogic approach to feedback was seen to be valuable as it contrasts with more formal monological aspects of ITE in which ATs are sometimes positioned as recipients of knowledge that has been constructed elsewhere (Charteris and Smardon, 2014). 
Respectful relationships between the PE mentors and the ATs were also seen to be fostered where there was a high regard for the professional teaching skills of the mentor. Care should be taken when selecting and matching mentors with ATs (Wright and Smith, 2000) as dialogic feedback was thought to be more effective when mentors could model best practice and were securely positioned as experts in their own practice (Charteris and Smardon, 2014). It was also thought to be useful when the mentors themselves were willing to reflect openly on their own teaching and model the desire to engage in ongoing professional learning (McGraw and Davis, 2017). In particular, positive and trusting relationships were noticeably enhanced when mentors asked the AT for advice on their own teaching. This line of questioning was shown to help reframe the relationship and develop a rapport thought to be necessary for the professional learning of ATs (Lofthouse and Wright, 2012).

Finally, establishing a collaborative mentor-AT relationship was also shown to be easier when the PE mentor was empathetic to the experience of an AT in the early stages of becoming a teacher. The feedback from mentors who were more recently qualified teachers was often valued by ATs as they had recently been through the same process. McGraw and Davis (2017) argue that mentors are better placed to provide empathetic feedback and build positively charged relationships when they themselves have experienced promoting personalised peer feedback and are still actively involved in professional learning (Kraft and Papay, 2014).

\section{Conclusion}

The impact of this research may be of most value for providers of ITE who typically focus mentor training around the well-established feedback mechanism of a formal written lesson observation. This criterion-based method of providing feedback is generally accepted by PE mentors and ATs in England as it fits with the conventions of gathering evidence against the national Teachers' Standards. While this approach undoubtedly has its place within mentor training, over-reliance on one formal method of providing feedback may promote a narrow conception of the mentoring process and preclude investigation of other, potentially valuable, means of providing feedback that are being adopted in schools. Moreover, the over-emphasis of a monological feedback model may unintentionally limit the progress of ATs. The formality of this criterion-based approach helps establish a hierarchical, expert-novice model, where ATs are positioned as more passive recipients of knowledge. This is characteristic of what Hobson and Malderez (2013) and Hobson (2016) called judgementoring, where one- 
way conversations about competency allow less room for reflection, innovation and discovery. Further research might usefully be carried out to explore the impact of engagement in dialogic mentoring and learning conversations on both mentors and ATs.

\section{Reference List}

Bokeno, R. and Gantt, V. (2000), "Dialogic mentoring: core relationships for organizational learning”, Management Communication Quarterly, Vol. 14 No. 2, pp. 237-270.

Bryman, A. (2012), Social research methods: fourth edition, Oxford University Press, Oxford, United Kingdom.

Cassidy, T., Jones, R. and Potrac, P. (2004), Understanding sports coaching: The social, cultural and pedagogical foundations of coaching practice, Routledge, Abingdon, United Kingdom.

Castanheira, P.S.P. (2016), "Mentoring for educators' professional learning and development", International Journal of Mentoring and Coaching in Education, Vol. 5 No. 4, pp. 334-346.

Charteris, J. and Smardon, D. (2014) "Dialogic peer coaching as teacher leadership for professional inquiry", International Journal of Mentoring and Coaching in Education, Vol. 3 No. 2, pp. 108-124.

Coe, R., Aloisi, C., Higgins, S. and Major, L.E. (2014), What makes great teaching? Review of the underpinning research, Project Report. Sutton Trust, London, United Kingdom.

Collet, V.S. (2015), "The Gradual Increase of Responsibility Model for coaching teachers", International Journal of Mentoring and Coaching in Education, Vol. 4 No. 4, pp. 269292.

Copland, F. (2010), "Causes of tension in post-observation feedback in pre-service teacher training: An alternative view", Teaching and Teacher Education, Vol. 26 No. 3, pp. 466-472.

Denzin, N. and Lincoln, Y. (2011), The SAGE handbook of qualitative research, Sage, London, United Kingdom.

Department for Education. (2013), “Teachers' Standards: Guidance for school leaders, school staff and governing bodies", available at: https://www.gov.uk/government/uploads/system/uploads/attachment_data/file/301107 /Teachers Standards.pdf (accessed 1 July 2017).

Garza, R., Duchaine, E., and Raynosa, R. (2014), "A year in the mentors' classroom: Perceptions of pre-service teachers in high needs schools", International Journal of Mentoring and Coaching in Education, Vol. 3 No.3, pp. 219-236.

Gratton, C. and Jones, I. (2010), Research Methods for Sports Studies, Routledge, London, United Kingdom.

Hattie, J. (2011), "Feedback in schools", in Sutton, R., Hornsey, M.J. and Douglas, K.M. (Eds.), Feedback: The communication of praise, criticism, and advice, Peter Lang Publishing, New York, NY, pp. 1-14.

Higgins, S., Katsipataki, M., Kokotsaki, D., Coleman, R., Major, L.E. and Coe, R. (2013), "The Sutton Trust Education Endowment Foundation Teaching and Learning 
Toolkit", available at: http://www.educationendowmentfoundation.org.uk/toolkit (accessed 1 July 2017).

Hinchey, P.H. (2010), Getting teacher assessment right: What policymakers can learn from research, National Education Policy Center, Boulder, CO.

Hobson, A.J. (2016), "Judgementoring and how to avert it: introducing ONSIDE Mentoring for beginning teachers", International Journal of Mentoring and Coaching in Education, Vol. 5 No.2, pp. 87-110.

Hobson, A.J. and Malderez, A. (2013), "Judgementoring and other threats to realizing the potential of school-based mentoring in teacher education", International Journal of Mentoring and Coaching in Education, Vol. 2 No. 2, pp. 89-108.

Isaacs, W. N. (1993), "Dialogue, collective thinking, and organizational learning", Organizational Dynamics, Vol. 22 No. 2, pp. 24-39.

James, M. and Pollard, A. (2011), “TLRP's ten principles for effective pedagogy: rationale, development, evidence, argument and impact", Research Papers in Education, Vol. 26 No. 3, pp. 275-328.

Ko, J., Sammons, P. and Bakkum, L. (2014), Effective Teaching, Education Development Trust, Reading, United Kingdom.

Kraft, M.A. and Papay, J.P. (2014), "Can Professional Environments in Schools Promote Teacher Development? Explaining Heterogeneity in Returns to Teaching Experience", Educational Evaluation and Policy Analysis, Vol. 36 No. 4, pp. 476500.

Lofthouse, R. (2017), “Improving Mentoring Practices through Collaborative Conversations", available https://www.schooleducationgateway.eu/en/pub/viewpoints/experts/improvingmentoring-practices-.htm (accessed 1 July 2017).

Lofthouse, R. and Wright, D. (2012), “Teacher education lesson observation as boundary crossing", International Journal of Mentoring and Coaching in Education, Vol. 1 No. 2, pp. 89-103.

McGraw, A. and Davis, R. (2017), "Mentoring for pre-service teachers and the use of inquiry-oriented feedback", International Journal of Mentoring and Coaching in Education, Vol. 6 No. 1, pp. 50-63.

Mullen, C.A. and Lick, D.W. (1991), New Directions in mentoring. Falmer Press, London, United Kingdom.

Nahmad-Williams, L. and Taylor, C.A. (2015), "Experimenting with dialogic mentoring: a new model", International Journal of Mentoring and Coaching in Education, Vol. 4 No. 3, pp.184-199.

Nicolaidou, M., Karagiorgi, Y. and Petridou, A. (2016), "Feedback-based coaching towards school leaders' professional development”, International Journal of Mentoring and Coaching in Education, Vol. 5 No. 1, pp. 20-36.

Roberts, K. (2009), Key concepts in sociology, Palgrave Macmillan, London, United Kingdom.

Senge, P. (1990), The Fifth Discipline: The Art and Practice of the Learning Organization, Currency Doubleday, New York. 
Shute, V.J. (2008), "Focus on Formative Feedback", Review of Educational Research, Vol. 78 No. 1, pp. 153-189.

Timperley, H., Wilson, A., Barrar, H. and Fung, I. (2007), "Teacher professional learning and development: Best evidence synthesis iteration", available at: http://www.educationcounts.govt.nz/publications/series/2515/15341 (accessed 1 July 2017).

Wang, J. and Odell, S.J. (2002), "Mentored Learning to Teach According to Standards-Based Reform: A Critical Review", Review of Educational Research, Vol. 72 No. 3, pp. 481-546.

Wright, S.C. and Smith, D.E. (2000), “A Case for Formalized Mentoring”, Quest, Vol. 52 No. 2, pp. 200-213. 